\title{
Equilibrium Price Dispersion with Sequential Search
}

\author{
Guido Menzio-University of Pennsylvania and NBER \\ Nicholas Trachter-Federal Reserve Bank of Richmond
}

February 14, 2014

\section{Introduction}

We propose a novel theory of equilibrium price dispersion in product markets with search frictions. As in Diamond (1971), buyers search for sellers sequentially. In contrast to Diamond (1971), buyers do not meet all sellers with the same probability. Specifically, a fraction of the buyers' meetings leads to one particular large seller, while the remaining fraction of the meetings leads to one of a continuum of small sellers. We prove that the unique equilibrium of this model is such that sellers post a non-degenerate distribution of prices and buyers capture a positive fraction of the gains from trade. The fraction of gains from trade accruing to the buyers is hump-shaped with respect to the market power of the large seller. However, for any degree of market power of the large seller, the fraction of gains from trade accruing to the buyers converges to one when search frictions vanish, and converges to zero when search frictions become arbitrarily large.

In a famous paper, Diamond (1971) analyzes a product market where buyers search sequentially for sellers. He finds that the equilibrium of this market is such that all sellers post the monopoly price and buyers capture none of the gains from trade. Moreover, he finds that this is the only equilibrium independently of the extent of search frictions. This result, which is popularly known as the Diamond Paradox, is problematic for several reasons. From the empirical point of view, the result flies against the evidence documenting that there is a great deal of price dispersion for identical goods (see, e.g, Sorensen 2000 or Kaplan and Menzio 2014). From the theoretical point of view, the result implies a puzzling discontinuity in outcomes because, without search frictions, all sellers would post the competitive price and buyers would capture all of the gains from trade. Yet the logic behind the Diamond Paradox is rather strong. Every seller wants to post the buyer's reservation price, i.e. the price that makes a buyer indifferent between purchasing the good and searching for another seller. But if every seller posts the same price, the option value of searching for another seller is zero and the buyer's reservation price must be equal to the monopoly price.

In a series of closely related papers, Butters (1977), Varian (1980) and Burdett and Judd (1983) consider an alternative environment which leads to equilibrium price dispersion and, in turn, to a resolution to the Diamond Paradox. In particular, they consider a search market where some buyers contact multiple sellers simultaneously, while other buyers contact one seller at a time. They find that, in equilibrium, sellers post different prices and buyers capture a positive fraction of the gains 
from trade. The intuition behind their result is clear. An equilibrium in which all sellers post the monopoly price (or any common price above the cost of production) cannot exist, as an individual seller would have an incentive to post a slightly lower price and trade not only with those buyers who have only contacted him, but also with those buyers who have contacted him as well as other sellers. This process of undercutting cannot lead to an equilibrium in which all sellers post a price equal to the cost of production, as an individual seller can always attain a strictly positive profit by charging a slightly higher price and trading only with buyers who have failed to contact multiple sellers. Hence, the equilibrium must involve a distribution of prices and buyers capture some of the gains from trade.

The assumption that some buyers contact multiple sellers simultaneously is quite strong. The assumption does not mean that there are some buyers that can freely recall previously contacted sellers. Even if some buyers could freely recall sellers, the only equilibrium would still be such that all sellers post the monopoly price and that buyers capture none of the gains from trade. The assumption really means that there are some buyers that come into contact with multiple sellers before being able to decide whether to stop searching. This observation motivates our paper, which advances a theory of equilibrium price dispersion in markets where search is genuinely sequential, in the sense that buyers have the option to stop searching after meeting any individual seller.

We consider a product market populated by buyers-each demanding one unit of an indivisible good-and sellers - each producing the good at the same cost. At the beginning of each day of trading, sellers first post prices, then buyers observe the price distribution and start searching for sellers. As in Diamond (1971), buyers search for sellers sequentially. However, in contrast to Diamond (1971), buyers do not meet all sellers with the same probability. Specifically, a fraction of the buyers' meetings leads to one particular large seller, while the remaining fraction of the meetings leads to one of a continuum of small sellers. We prove that an equilibrium in this market exists and is unique. In equilibrium, the large seller randomizes over his price from a distribution whose support is a closed, convex, non-empty subset of the interval between the sellers' cost and the buyers' valuation of the good. The small sellers post a distribution of prices whose support is also a closed, convex and non-empty subset of the interval between cost and valuation of the good. The buyers capture a positive fraction of the gains from trade, which varies depending on the realization of the large seller's price.

The intuition behind these results is straightforward. First, it is easy to rule out an equilibrium in which large and small sellers post a common price. An equilibrium in which all sellers post the monopoly price cannot exist because the large seller could increase its profits by posting a slightly lower price. In fact, by doing so, the large seller would push the buyer's reservation price below the small sellers' price and, hence, it would increase the number of buyers that purchase the good from him. An equilibrium in which all sellers post a common price below the monopoly price also cannot exist. On the one hand, if all sellers post a price below the buyer's reservation price, then a 
small seller could increase his profit by raising the price. If, on the other hand, all sellers post a price equal to the buyers' reservation price, the reservation price would be equal to the monopoly price, a case that we already ruled out.

It is also easy to understand why there is no equilibrium in which the small sellers post a common price. If the small sellers post the same price, the large seller has no incentive to randomize over his price. This implies that the small sellers can perfectly forecast the buyers' value of search and they will all post exactly the buyers' reservation price. If the large seller's price is below the reservation price, we do not have equilibrium, as the large seller could increase his profit by raising the price. If the large seller's price is equal to the reservation price, all sellers would be posting a common price, which is a case that we have already ruled out. Hence, the equilibrium must be such that the small sellers post a non-degenerate distribution of prices and, hence, such that the buyers capture a positive fraction of the gains from trade.

The equilibrium outcomes in our model depend critically on two parameters: the market power of the large seller-as measured by the fraction of buyers' meetings that involve the large sellerand the extent of search frictions-as measured by the rate at which buyers meet sellers. We find that the competitiveness of the market is non-monotonic with respect to the market power of the large seller. When the market power of the large seller vanishes, the environment converges to the one studied by Diamond (1971) and the equilibrium outcomes converges to those of a pure monopoly. In particular, the distributions of prices posted by the large and the small sellers converge to the monopoly price and the fraction of the gains from trade accruing to the buyers goes to zero. Similarly, when the market power of the large seller becomes complete, the equilibrium outcomes converge to those of a pure monopoly. However, whenever the market power of the large seller is positive but finite, there is price dispersion and buyers capture a positive fraction of the gains from trade. Thus, the Diamond Paradox can be viewed as the limit of a paradoxically non-monotonic relationship between the market power of the large seller and the extent of competition.

Whenever the market power of the large seller is positive and finite, the competitiveness of the market depends in a natural way on the extent of search frictions. When the search frictions become arbitrarily small, the equilibrium outcomes converge to those of a perfectly competitive market. In particular, the distributions of prices posted by the large and the small sellers converge to the competitive price and the fraction of the gains from trade accruing to the buyers converges to one. In contrast, when the search frictions become arbitrarily large, the equilibrium outcomes converge to those of a pure monopoly. Thus, whenever the market power of the large seller is positive and finite, the discontinuity in equilibrium outcomes highlighted by Diamond (1971) disappears: when search frictions vanish, the equilibrium becomes competitive. 
Our paper adds to the existing theories of equilibrium price dispersion in product markets with search frictions. As mentioned above, Butters (1977), Varian (1982) and Burdett and Judd (1983) generate price dispersion in the context of a model where search is sometimes sequential and sometimes simultaneous. In contrast, we obtain price dispersion in a model where search is genuinely sequential. Albrecht and Axell (1984) obtain price dispersion in a model of sequential search by introducing heterogeneity in buyers' valuations. However, their model is such that the Diamond Paradox holds for the buyers with the lowest valuation. Hence, in the presence of an entry cost, the lowest valuation buyers would stay out of the market and price dispersion would unravel. In contrast, our theory of price dispersion is robust to the introduction of entry costs. Benabou (1989) obtains price dispersion in a model of sequential search by introducing inflation and costs to adjust nominal prices. In contrast, our theory of price dispersion does not rely on nominal rigidities.

There are also several theories that resolve the Diamond Paradox without generating price dispersion. Pissarides (1984) and Mortensen and Pissarides (1994) show that, if prices are determined as the outcome of a bargaining game between buyers and sellers rather than being posted by sellers, then buyers will generally capture a positive fraction of the gains from trade. Moen (1997) and Burdett, Shi and Wright (2001) show that, if buyers can direct their search towards particular sellers, then sellers will compete for searchers and buyers will generally end up capturing a fraction of the gains from trade. Carrillo-Tudela, Menzio and Smith (2011) show that, if buyers can recall past sellers and sellers can distinguish between buyers with single and multiple contacts, then buyers capture some of the gains from trade. 